\title{
BAURAN PEMASARAN (4P+PHYSICAL EVIDENCE) DAN PENGARUHNYA TERHADAP KEPUTUSAN KONSUMEN DALAM MENGGUNAKAN JASA LABORATORIUM KLINIK PRODIA SURAKARTA
}

\author{
Sarsi Hartiningsih \\ STIE Atma Bhakti Surakarta \\ Email : sarsi.sasa@gmail.com \\ Betty Eliya Rokhmah \\ STIE Atma Bhakti Surakarta \\ Email : eliya.rokhmah@gmail.com
}

\begin{abstract}
Abstrak
Tujuan penelitian ini adalah untuk mengetahui pengaruh masing-masing variabel produk, harga, promosi, saluran distribusi dan bukti fisik terhadap keputusan konsumen dalam menggunakan jasa Laboratorium Klinik Prodia di Surakarta. Sampel penelitian adalah 75 orang konsumen. Hasil uji instrument data menunjukan bahwa setiap variabel bauran pemasaran $(5 \mathrm{P})$ mempunyai nilai $r$ hitung $>\mathrm{r}$ tabel dan nilai cronbach's alpha $>0.60$ sehingga data bersifat valid dan reliabel dan dapat digunakan untuk penelitian selanjutnya. Hasil uji hipotesis menunjukkan bahwa masing-masing variabel produk, harga, promosi, saluran distribusi dan bukti fisik mempunyai nilai $t$ hitung $>\mathrm{t}$ tabel dengan nilai signifikasi $<0.05$ sehingga dapat disimpulkan bahwa produk, harga, promosi, saluran distribusi dan bukti fisik berpengaruh positif dan signifikan terhadap keputusan konsumen dalam menggunakan jasa Laboratorium Klinik Prodia
\end{abstract}

Kata kunci: produk, harga, promosi, saluran distribusi dan bukti fisik keputusan konsumen.

\begin{abstract}
The purpose of this study was to determine the effect of each variable product, price, promotion, distribution channels and the physical evidence against the customers decision in using the services of Prodia Clinical Laboratory in Surakarta. The samples used were 75 consumers. Instrument test result data indicates that every marketing mix variables (5P) has the highest $r$ count $>r$ table and Cronbach's alpha values $>0.60$ so that the data is valid and reliable and can be used for further research. Hypothesis test results show that each variable product, price, promotion, distribution channels and physical evidence has the value $t$ count $>t$ table with a significance value of $<0.05$, so it can be concluded that the product, price, promotion, distribution channels and physical evidence, each has positive and significant impact on customers decisions in using the services of the Prodia Clinical Laboratory.
\end{abstract}

Keyword: product, price, promotion, distribution channels, physical evidence, customers decision 


\section{PENDAHULUAN}

Setiap orang membutuhkan kesehatan dikarenakan kesehatan merupakan hal yang vital bagi kehidupan. Begitu pentingnya kesehatan ini membuat banyak perusahaan yang berminat untuk membuka bisnis di bidang kesehatan diantaranya laboratorium klinik. Laboratorium klinik merupakan tempat untuk melakukan pemeriksaan seluruh anggota tubuh yang lebih spesifik. Penggunaan laboratorium klinik pada dasarnya adalah untuk memeriksa terkait organ dalam seseorang, hal ini akan mendorong masyarakat yang merupakan konsumen untuk mendapatkan hasil produk dengan keakuratan tinggi, pelayanan yang bagus, lokasi yang mudah dijangkau serta harga yang terjangkau pula serta memberikan promosi-promosi tertentu. Kualitas produk, harga, lokasi maupun promosi yang ditawarkan merupakan dimensi dari bauran pemasaran.

Stanton (2000) menyatakan bahwa pemasaran adalah suatu sistem keseluruhan dari kegiatan-kegiatan bisnis yang ditujukan untuk merencanakan, menentukan harga, mempromosikan dan mendistribusikan barang dan jasa yang memuaskan kebutuhan baik kepada pembeli yang ada maupun pembeli potensial. Bauran pemasaran adalah kombinasi dari empat variabel yaitu produk, struktur harga, kegiatan promosi, dan sistem distribusi (Swastha, 2007).

Bauran pemasaran diketahui memberikan pengaruh terhadap Keputusan
Konsumen Pengguna Jasa (Martutik, 2010). Penelitian yang dilakukan Wilopo (2013) menunjukan bahwa variabel dimensi bauran pemasaran secara bersamasama atau simultan mempunyai pengaruh yang signifikan terhadap proses keputusan menabung nasabah. Penelitian Lisnawati (2013) memberikan kesimpulan bahwa bauran pemasaran memberikan pengaruh terhadap keputusan anggota dalam menggunakan pembiayaan murabahah.

Penawaran jasa (non fisik) akan memberikan keunikan tersendiri bila dibandingkan dengan penawaran produk (fisik). Meskipun kadang keputusan pembelian konsumen menunjukkan hasil yang sama, akan tetapi penawaran jasa membutuhkan pendekatan yang berbeda terhadap konsumennya agar konsumen mau menggunakan jasa yang ditawarkan. Oleh karena itu dalam penelitian kali ini akan meneliti tentang bagaimana pengaruh bauran pemasaran yang terdiri dari produk, harga, lokasi, dan promosi terhadap keputusan konsumen. Selain bauran pemasaran yang terdiri dari empat variabel di atas, penelitian ini juga turut menambahkan variabel bukti fisik dikarenakan variabel ini dapat menggambarkan bagaimana seorang konsumen mendapatkan bukti yang nyata dari jasa yang ditawarkan.

\section{MODEL DAN HIPOTESIS PENELITIAN}

Model penelitian ini dapat dilihat pada Gambar 1.

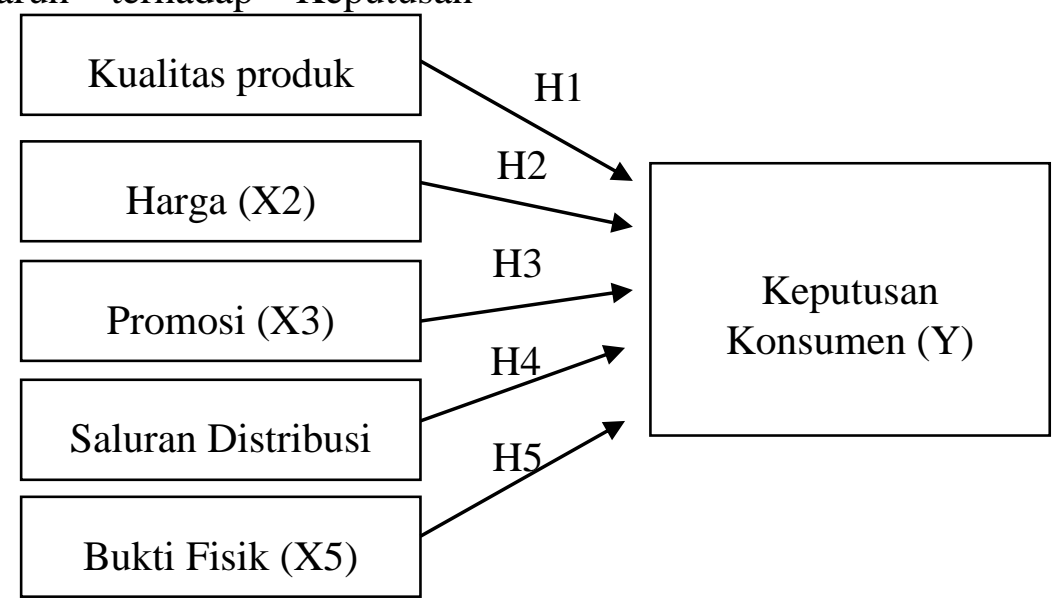

Gambar 1. Model Penelitian 


\section{Hipotesis} adalah :

Hipotesis penelitian yang diajukan

H1 : Kualitas produk berpengaruh positif dan signifikan terhadap keputusan konsumen dalam menggunakan jasa Laboratorium Klinik Prodia di Surakarta.

H2 : Harga berpengaruh positif dan signifikan terhadap keputusan konsumen dalam menggunakan jasa Laboratorium Klinik Prodia di Surakarta.

H3 : Promosi berpengaruh positif dan signifikan terhadap keputusan konsumen dalam menggunakan jasa Laboratorium Klinik Prodia di Surakarta.

H4 : Saluran distribusi berpengaruh positif dan signifikan terhadap keputusan konsumen dalam menggunakan jasa Laboratorium Klinik Prodia di Surakarta.

H5 : Bukti fisik berpengaruh positif dan signifikan terhadap keputusan konsumen dalam menggunakan jasa Laboratorium Klinik Prodia di Surakarta.

\section{METODE PENELITIAN}

Objek dalam penelitian ini adalah laboratorium klinik Prodia Surakarta yang mempunyai kualitas produk yang bagus, dengan pilihan paket pemeriksaan dengan harga yang variatif, sering memberikan promosi, serta mempunyai lokasi yang berada dipusat kota sehingga mudah dijangkau oleh konsumen. Populasi dalam penelitian ini adalah pelanggan Laboratorium Klinik Prodia Surakarta, sedangkan sampel yang diambil secara qonvinience sampling sebanyak 75 responden.

Untuk variabel keputusan konsumen indikator yang digunakan adalah kualitas hasil pemeriksaan klinik, harga yang terjangkau, promosi yang dilakukan, lokasi yang mudah dijangkau, serta fasilitas yang lengkap.
Variabel produk indikatornya terdiri dari kualitas hasil pemeriksaan klinik, berbagai macam pilihan pemeriksaan klinik yang diberikan, jaminan kerahasian hasil pemeriksaan klinik, dan keamanan hasil pemeriksaan karena dilindungi oleh cover yang kuat.

Variabel harga menggunakan indikator harga sesuai dengan kualitas hasil pemeriksaan, harga yang bersaing dengan tempat lain, pilihan harga yang diberikan bermacam-macam, harga Panel Check Up yang terjangkau dibandingkan tempat lain.

Variabel promosi indikatornya adalah potongan harga yang diberikan pada item-item tertentu, media promosi yang digunakan beragam, promosi sering dilakukan, promosi mudah dimengerti dan bisa tertanam baik dihati konsumen.

Variabel saluran distribusi/lokasi indikatornya adalah lokasi yang strategis di pusat kota, lokasi mudah dijangkau, adanya fasilitas pengiriman hasil pemeriksaan ke konsumen, kecepatan dalam pengiriman hasil pemeriksaan ke konsumen.

Variabel bukti fisik indikatornya adalah ruang tunggu pasien yang nyaman, ruang pemeriksaan yang bersih dan rapi, menyediakan informasi pemeriksaan lengkap dan detail, kerapian dan kesopanan seragam yang dipakai karyawan.

\section{ANALISIS DATA}

Hasil uji reliabilitas ditampilkan pada Tabel 1.

Tabel 1. Uji Reliabilitas

\begin{tabular}{lc}
\hline \multicolumn{1}{c}{ Variabel } & $\begin{array}{c}\text { Nilai Cronbach } \\
\text { Alpha }(\boldsymbol{a})\end{array}$ \\
\hline Produk (X1) & 0.800 \\
\hline Harga (X2) & 0.787 \\
\hline Promosi (X3) & 0.783 \\
\hline Saluran Distribusi (X4) & 0.718 \\
\hline Bukti Fisik (X5) & 0.750 \\
\hline Keputusan Konsumen (Y) & 0.767 \\
\hline Sumber : Olah data primer 2015
\end{tabular}

Sumber : Olah data primer 2015 


\section{Uji Hipotesis}

Teknik analisis data dalam penelitian ini menggunakan analisis regresi linier berganda. Analisis regresi linier berganda adalah teknik statistik yang digunakan untuk mengestimasi pengaruh variabel independen terhadap variabel dependen. Hasil uji F, $\mathrm{R}^{2}$, dan hasil analisis persamaan regresi linier berganda dapat dilihat pada Tabel 2, Tabel 3, dan Tabel 4.

Tabel 2. Hasil Uji F

\begin{tabular}{llll}
\hline Model & & F & Sig. \\
\hline 1 & Regression & 23.647 & $.000^{\mathrm{a}}$ \\
\hline
\end{tabular}

Dari hasil pengolahan pada Tabel 2 didapatkan tingkat signifikansi 0,000 , nilai ini lebih kecil dari 0,005 atau nilai $\mathrm{Sig}<\alpha$. Selain itu didapatkan F hitung sebesar 23,647 sedangkan $F$ tabel sebesar 2,503, hal ini menunjukkan $\mathrm{F}$ hitung $>\mathrm{F}$ tabel. Dengan demikian seluruh variabel independen (yaitu produk, harga, promosi, bukti fisik dan saluran distribusi) secara bersama-sama memiliki pengaruh yang signifikan terhadap keputusan konsumen.

Tabel 3. Hasil Uji $\mathrm{R}^{2}$

\begin{tabular}{cccc}
\hline Model & $\mathrm{R}$ & R Square & $\begin{array}{c}\text { Adjusted R } \\
\text { Square }\end{array}$ \\
\hline 1 & $.795^{\mathrm{a}}$ & .631 & .605 \\
\hline
\end{tabular}

Dari Tabel 3 didapatkan nilai $\mathrm{R}$ sebesar 0,795, hal ini menunjukkan bahwa korelasi antara variabel dependen dengan variabel independen adalah kuat. Sedangkan nilai $\mathrm{R}^{2}$ sebesar 0,605 menunjukkan bahwa sebesar 60,5\% keputusan konsumen dapat dijelaskan oleh variabel harga, promosi, produk, bukti fisik serta saluran distribusi. Sedangkan sisanya sebesar $39,5 \%$ dapat dijelaskan oleh variabel lain yang tidak diteliti.
Tabel 4. Hasil Analisis Persamaan Regresi Linier Berganda

\begin{tabular}{lc}
\hline \multicolumn{1}{c}{ Variabel } & Nilai Beta $(\boldsymbol{\beta})$ \\
\hline Produk (X1) & 0.311 \\
\hline Harga (X2) & 0.203 \\
\hline Promosi (X3) & 0.182 \\
\hline Saluran Distribusi (X4) & 0.214 \\
\hline Bukti Fisik (X5) & 0.306 \\
\hline
\end{tabular}

Sumber : Olah data primer 2015

\section{PEMBAHASAN}

Pengaruh Kualitas Produk terhadap Keputusan Konsumen

Kualitas produk berpengaruh positif dan signifikan terhadap keputusan konsumen dalam menggunakan jasa Laboratorium Klinik Prodia di Surakarta, dengan demikian $\mathrm{H} 1$ diterima. Hal ini sesuai dengan penelitian Martutik (2010) yang menemukan bahwa variabel produk berpengaruh positif dan signifikan terhadap keputusan konsumen, Wilopo (2013) juga menemukan bahwa variabel produk merupakan variabel yang berpengaruh dominan terhadap keputusan seseorang untuk menggunakan jasa pada Bank Muamalat.

\section{Pengaruh Harga terhadap Keputusan Konsumen}

Hasil peneilitiam disimpulkan bahwa kebijakan harga berpengaruh positif dan signifikan terhadap keputusan konsumen dalam menggunakan jasa Laboratorium Klinik Prodia di Surakarta dengan demikian $\mathrm{H} 2$ diterima. Penelitian sebelumnya yang dilakukan oleh Lisnawati (2013) yang menemukan bahwa variabel harga berpengaruh positif dan signifikan teradap keputusan konsumen turut mendukung hasil penelitian ini.

\section{Pengaruh Promosi terhadap Keputusan Konsumen}

Hasil penelitian disimpulkan bahwa kegiatan promosi maupun pemberian promosi berpengaruh positif dan signifikan terhadap keputusan konsumen dalam menggunakan jasa Laboratorium Klinik 
Prodia di Surakarta dengan demikian H3 diterima. Hal ini sesuai dengan penelitian yang dilakukan Achidah et al. (2016) dan Irawan (2014) yang menemukan bahwa promosi berpengaruh terhadap keputusan pembelian konsumen.

\section{Pengaruh Saluran Distribusi terhadap Keputusan Konsumen}

Hasil penelitian disimpulkan kegiatan saluran distirbusi berpengaruh positif dan signifikan terhadap keputusan konsumen dalam menggunakan jasa Laboratorium Klinik Prodia di Surakarta dengan demikian $\mathrm{H} 4$ diterima. Penelitian Silviana (2013) dan Lestari et al. (2012) menemukan bahwa saluran distribusi berpengaruh positif dan signifikan terhadap keputusan konsumen sehingga turut mendukung hasil penelitian ini.

\section{Pengaruh Bukti Fisik terhadap Keputusan Konsumen}

Hasil penelitian disimpulkan bahwa bukti fisik yang diberikan perusahaan kepada konsumen berpengaruh positif dan signifikan terhadap keputusan konsumen dalam menggunakan jasa Laboratorium Klinik Prodia di Surakarta dengan demikian H5 diterima. Hal ini sesuai dengan penelitian Wati dan Satrio (2015) serta Harriyanto (2013) yang menemukan bahwa bukti fisik berpengaruh terhadap keputusan konsumen.

\section{PENUTUP}

\section{Kesimpulan}

Setelah dilakukan olah data serta mendapatkan hasil dari olah data tersebut, maka dapat diambil kesimpulan sebagai berikut:

1. H1 menyatakan kualitas produk berpengaruh positif dan signifikan terhadap keputusan konsumen dalam menggunakan jasa Laboratorium Klinik Prodia di Surakarta. Hasil penelitian tersebut menunjukkan bahwa konsumen menilai bahwa Laboratorium Klinik Prodia memberikan hasil pemeriksaan yang akurat dan menjamin kerahasiaan hasil pemeriksaan serta hasil pemeriksaan juga terlindungi dengan aman karena bungkus/cover yang kuat. Selain itu Laboratorium Klinik Prodia juga menyediakan pemeriksaan klinik yang lengkap dan bermacam-macam sehingga konsumen mempunyai banyak pilihan dalam memilih suatu pemeriksaan yang dibutuhkan.

2. H2 menyatakan harga berpengaruh positif dan signifikan terhadap keputusan konsumen dalam menggunakan jasa Laboratorium Klinik Prodia di Surakarta. Hasil penelitian tersebut menunjukkan bahwa konsumen merasa jika harga yang ditawarkan setiap paket pemeriksaan sesuai dengan keakuratan hasil pemeriksaan selain itu pada paket pemeriksaan tertentu harga yang ditawarkan laboratorium klinik Prodia lebih murah dibandingkan dengan tempat yang lain. Khususnya pemeriksaan panel check up di Laboratorium Klinik Prodia lebih terjangkau dari pada laboratorium klinik lainnya serta Laboratorium Klinik Prodia juga menawarkan paket pemeriksaan dengan harga yang menarik dan sesuai dengan kebutuhan pasiennya.

3. H3 menyatakan promosi berpengaruh positif dan signifikan terhadap keputusan konsumen dalam menggunakan jasa Laboratorium Klinik Prodia di Surakarta. Hal ini dikarenakan konsumen tertarik dengan adanya promosi diskon atau potongan harga yang ditawarkan pada item-item pemeriksaan tertentu. Konsumen juga merasa bahwa Laboratorium Klinik Prodia sering melakukan promosi dengan baik dan optimal mulai dari menyebarkan brosur dan mengumumkan dengan media cetak dan elektronik. Promosi yang dilakukan juga mudah dimengerti dikemas dengan bahasa dan desain yang menarik.

4. H4 menyatakan saluran distribusi berpengaruh positif dan signifikan terhadap keputusan konsumen dalam 
menggunakan jasa Laboratorium Klinik Prodia di Surakarta. Hal ini dikarenakan konsumen merasa mudah untuk menjangkau Laboratorium Klinik Prodia karena terletak dipusat kota dan dapat dijangkau dengan berbagai sarana transportasi darat. Konsumen lebih tertarik lagi terhadap Laboratorium Klinik Prodia karena adanya pelayanan pengiriman hasil pemeriksaan kerumah pasien dengan cepat dan tepat.

5. H5 menyatakan bukti fisik berpengaruh positif dan signifikan terhadap keputusan konsumen dalam menggunakan jasa Laboratorium Klinik Prodia di Surakarta. Hal ini dikarenakan pasien merasa Laboratorium Klinik Prodia mempunyai ruang tunggu pasien yang nyaman, ruang pemeriksaan yang bersih dan rapi, karyawan juga menggunakan seragam dengan rapi dan sopan dan Laboratorium Klinik Prodia juga memberikan informasi pemeriksaan yang lengkap dan detail.

\section{DAFTAR PUSTAKA}

Achidah, N., Warso, M.M. \& Hasiholan, L. B. (2016). Pengaruh Promosi, Harga, dan Desain terhadap Keputusan Pembelian Sepeda Motor Mio GT (Studi Empiris pada Produk Yamaha Mio GT di WeleriKendal). Journal of Management, 2(2).

Assauri, S. (2004). Manajemen Produksi dan Operasi. Jakarta: Lembaga Fakultas Ekonomi Universitas Indonesia.

Alma, B. (2004). Manajemen Pemasaran dan Pemasaran Jasa. Bandung: Alfabeta.
Harriyanto. (2013). Analisis pengaruh Bauran Pemasaran Jasa terhadap Keputusan Pembelian pada PT. Adira Quantum Multifinance Cabang Padang. Skripsi. Universitas Taman Siswa. Padang.

Irawan, P. D. (2014). Pengaruh Strategi Promosi Terhadap Keputusan Pembelian yang Dimediasi oleh Minat Beli pada Konsumen Matahari Department Store Yogyakarta. Skripsi : UNY.

Kotler, P. (2002). Manajemen Pemasaran, Jilid 1. Jakarta: Prehallindo.

Kotler, P. (2003). Manajemen Panduan Riset Perilaku Konsumen. Jakarta: PT. Pustaka Gramedia Utama.

Kotler, P. (2005). Manajamen Pemasaran, Jilid 1 dan 2. Jakarta: PT. Indeks. Kelompok Gramedia.

Kotler \& Amstrong. (2004). PrinsipPrinsip Marketing. Jakarta: Salemba Empat.

Lestari, S., Hasiolan, \& Haryono. (2012). Pengaruh Kualitas Produk, Saluran Distribusi dan Strategi Pemasaran terhadap Keputusan Pembelian CV. Davindo Jaya Semarang. Universitas Pandanaran Semarang.

Lisnawati. (2013). Pengaruh Bauran Pemasaran Terhadap Keputusan Anggota dalam menggunakan pembiayaan Murabahah (Studi Pada Produk Jasa Keuangan Mikro di BMT Mitrama). Yogyakarta. 
Silviana, M. (2013). Pengaruh Produk, Harga, Promosi, dan Saluran Distribusi terhadap Keputusan Pembelian Ulang Ice Cream Wall' s pada Siswa SMP dan SMA di Kota Padang. Universitas Negeri Padang.

Stanton, W.J . (2000). Prinsip Pemasaran. Edisi 1. Jakarta: Erlangga.

Subagio, A. (2010). Marketing In Business. Jakarta: Mitra Wacana Media

Swastha, B. \& Irawan. (2007). Manajemen Pemasaran Modern. Jakarta: Fakultas Ekonomi Universitas Indonesia

Tjiptono, F. (2008). Strategi Pemasaran. Yogyakarta : Andi Offset.

Martutik, A. T. (2010). Pengaruh Bauran Pemasaran Terhadap Keputusan Konsumen Pengguna Jasa Catering Pada PT. Sonokembang Wahana Jaya Malan. Malang.

Wati, U. I., \& Satrio, B. (2015). Pengaruh Bauran Pemasaran Jasa terhadap Keputusan Siswa Memilih SMA Barunawati Surabaya. Jurnal Ilmu dan Riset Manajemen. 4(7).

Wilopo. (2013). Pengaruh bauran pemasaran jasa terhadap Кериtusan menabung (Survei Pada Nasabah Bank Muamalat Cabang Malang). Malang. 